\title{
Impact of nonpharmacological COVID-19 interventions in hospitalizations for pneumonia in Brazil
}

\author{
Frederico Friedrich ${ }^{1}$, Laura e Garcia ${ }^{1}$, Lucas Petry ${ }^{1}$, Marina Pieta ${ }^{1}$, Gustavo Carvalho ${ }^{1}$, \\ Giovani Zocche ${ }^{1}$, Renata Ongaratto ${ }^{2}$, Magali Lumertz ${ }^{1}$, Marcos Brum ${ }^{1}$, Renato Stein ${ }^{3}$, \\ Marcelo Scotta ${ }^{4}$, Marcus Jones ${ }^{5}$, and Leonardo Pinto ${ }^{2}$ \\ ${ }^{1}$ Pontifical Catholic University of Rio Grande do Sul Faculty of Medicine \\ ${ }^{2}$ Pontificia Universidade Catolica do Rio Grande do Sul \\ ${ }^{3}$ Pontificia Universidade Catolica, Brazil \\ ${ }^{4}$ Biomedical Research Institute, Pontifícia Universidade Católica do Rio Grande do Sul \\ ${ }^{5}$ PUCRS
}

April 23, 2021

\begin{abstract}
Background and Objective: The knowledge about the impact of the nonpharmacological measures to control the COVID-19 pandemic can give insight to ways in which they can also be applied for other respiratory diseases. To assess the impact of containment measures of the COVID-19 pandemic on pneumonia hospitalizations in children from 0 to 14 years of age in Brazil. Methods: Data from hospital admissions for pneumonia were obtained from the Department of Informatics of Brazilian Public Health System database in the period of 2015-2020 and analyzed by macro-regions and age groups. To evaluate the effect of containment measures, used in the pandemic, on the incidence of pneumonia, the absolute reduction and relative reduction were calculated by analyzing the subsets 2015-2019 vs 2020. Results: Comparing the subsets of April-August 2015-2019 vs April-August 2020, there was an expressive reduction in the average incidence of hospitalizations, with numbers ranging from $-87 \%$ [IRR 0.12 ( 0.10 to 0.14$)$ ] for < 4 years, $-79 \%$ [IRR 0.21 ( 0.07 to 0.57$)$ ] for $5-9$ years, $-73 \%$ [IRR 0.26 (0.05 to 1.21$)$ ] for 10-14 and $-86 \%$ [IRR 0.14 (0.06 to 0.29)] for <14 years. Conclusion: We found a significant decrease in cases of pneumonia during the COVID-19 pandemic. Nonpharmacological public health interventions can contribute to the decline of other respiratory infectious diseases.
\end{abstract}

\section{Hosted file}

manuscript_major_pnm_20_04_2021.pdf available at https://authorea.com/users/409574/articles/ 519199-impact-of-nonpharmacological-covid-19-interventions-in-hospitalizations-forpneumonia-in-brazil

\section{Hosted file}

Table_one_pnm_20_04_2021.pdf available at https://authorea.com/users/409574/articles/519199impact-of-nonpharmacological-covid-19-interventions-in-hospitalizations-for-pneumoniain-brazil 

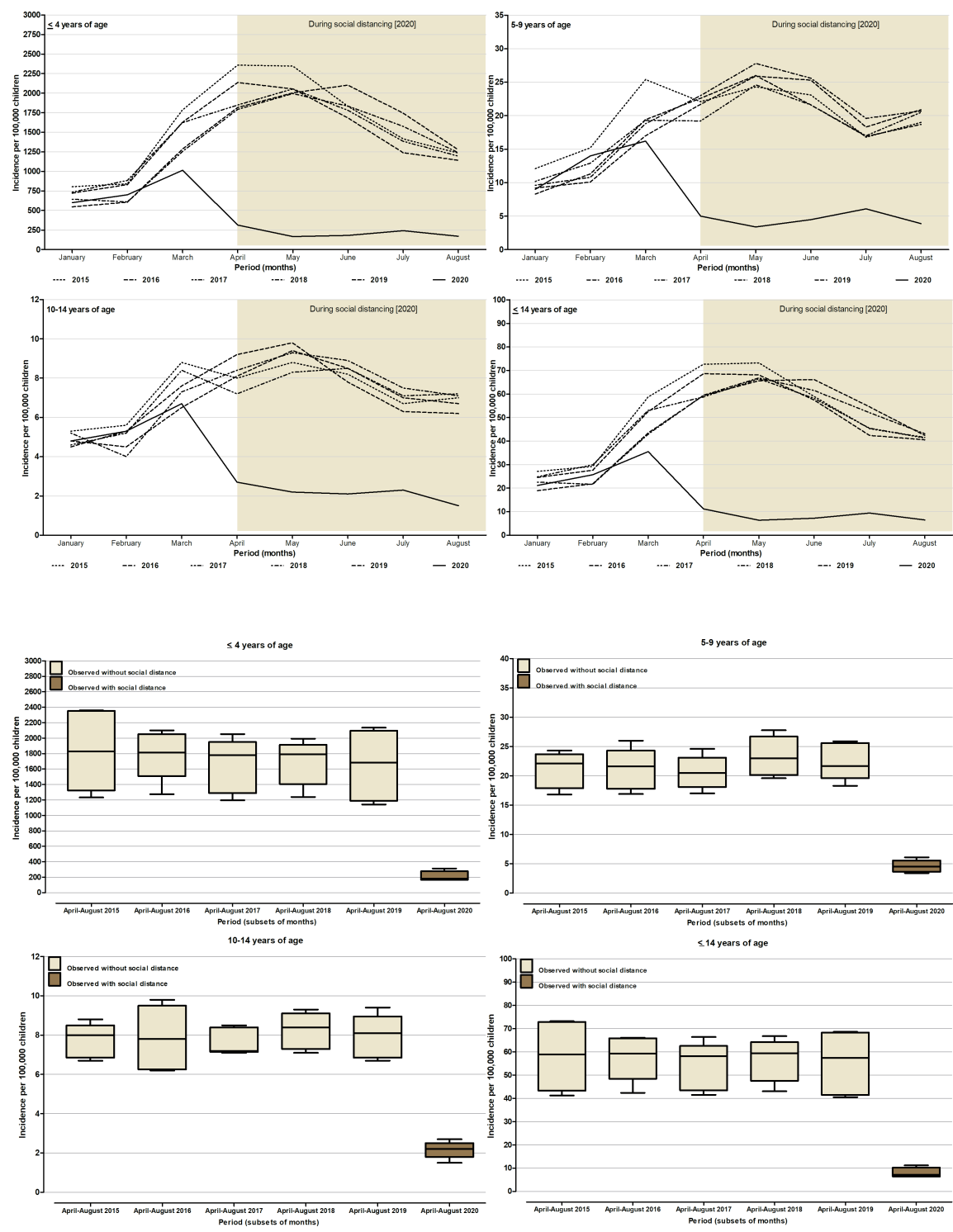